\title{
Daños estructurales en construcciones patrimoniales de la Iglesia Católica en la Arquidiócesis de Concepción producto del sismo del 27 de febrero 2010
}

\author{
Structural damages in the Catholic Church heritage constructions of the Concepción \\ Archdiocese due to the earthquake of 27 February 2010
}

Fecha de entrega: 28 de julio 2011

Fecha de aceptación: 17 de octubre 2011

\section{Guillermo Bustamante y Rafael Aránguiz}

Departamento de Ingeniería Civil, Universidad Católica de la Santísima Concepción, Alonso de Ribera 2850, Concepción, Chile, gbustamante@ucsc.cl, raranguiz@ucsc.cl

El 27 de febrero del 2010 a las 3:34am (hora local), la zona centro-sur de Chile fue sacudida por un terremoto magnitud momento 8,8. A consecuencia de ello varias iglesias de la Arquidiócesis de Concepción sufrieron daños desde menores hasta algunas que tuvieron que ser demolidas o que simplemente colapsaron en el mismo instante del terremoto. Por lo anterior, las autoridades de la Universidad Católica de la Santísima Concepción pidieron se conformara una comisión para revisar estas iglesias y capillas. A través de un trabajo de ingenieros, arquitectos y constructores que constituyeron esta comisión, se logró tener una evaluación de estas construcciones. En esta evaluación se identificaron algunas fallas típicas propias de este tipo de construcción que evidenciaron que frente a movimientos telúricos de esta magnitud era claro que fallarían. Por eso este trabajo también trata de la identificación de estas fallas y entregar recomendaciones para que no se vuelvan a producir.

Palabras clave: terremotos fuertes, estructuras patrimoniales, daños, reparación
The $27^{\text {th }}$ of February 2010 at 3.34am (local time), the CentralSouth part of Chile was shaken by an 8.8 earthquake moment magnitude. As a consequence, several churches of the Concepción Archdiocese suffered damages. Some of them had minor damages and others were demolished or simply collapsed during the earthquake event. As a result, the authorities of the Catholic University of Concepción asked for a commission to check these churches and chapels. Through the work of engineers, architects and constructors, members of the commission, it was possible to evaluate these buildings. In this evaluation, some typical failures expected for this type of buildings facing strong seismic movements, were identified. Therefore, this work also deals with identification and recommendations of repairing to avoid failures in future earthquakes.

Keywords: strong earthquakes, heritage structures, damage, repairing

Se entregan algunos aspectos generales del sismo del 27/02/2010 y una comparación con otros eventos ocurridos en tiempos pasados. Además se presenta una descripción de las estructuras resistentes, los daños observados y se realiza un análisis de las causas de dichos daños. Esta información fue parte de los informes estructurales utilizados para su reparación. Las estructuras inspeccionadas corresponden a la Catedral de Concepción, El Sagrario y la Iglesia La Pompeya, todas ubicadas en el centro de Concepción. Además, se inspeccionó el Templo Parroquial Jesús Obrero, ubicado en el sector Schwager de Coronel y el Santuario de Yumbel. La Figura 1 muestra la ubicación 
geográfica de las estructuras inspeccionadas de Yumbel y Schwager respecto a Concepción.

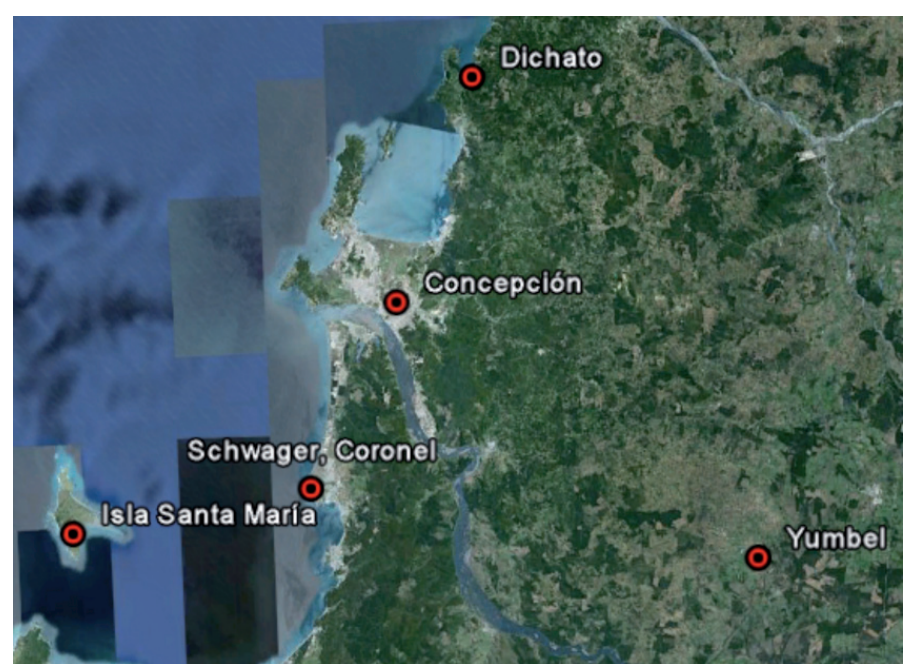

Figura 1: Mapa de ubicación de las estructuras inspeccionadas, se indican también otros puntos de referencia

A pesar de que se han publicado trabajos sobre los efectos del terremoto del 27 de febrero 2010, estos han sido principalmente sobre daños en edificios habitacionales y en estructuras industriales (GEER 2010, Betanzo, 2010). Es por ello que este trabajo aporta en la investigación de estructuras de iglesias, las cuales son en general más antiguas y por lo tanto ya han sufrido antes grandes terremotos.

\section{Aspectos generales del sismo}

El sismo del 27 de febrero del año 2010, de magnitud momento 8.8, tuvo su epicentro en las costas de Cobquecura, región del Bío Bío. Para mayor información sobre este terremoto revisar Barrientos (2010) y Quezada et al. (2010). La Figura 2 muestra la localización del epicentro, el cual se ubicó a $100 \mathrm{~km}$ al norte de la ciudad de Concepción, lo que explica la gran intensidad del sismo en esta zona.

La intensidad de un sismo se mide mediante la escala de Mercalli. Esta escala posee 12 grados y mide la intensidad en un lugar específico. Por lo tanto refleja la sensación que perciben las personas de tal lugar de ese movimiento telúrico y del estado en que quedan las estructuras, luego de una evaluación estructural, en caso de intensidades mayores a VI. Para una descripción de los grados de la escala de Mercalli modificada, ver por ejemplo Sauter (1989). De este modo, se pueden reportar varias intensidades para un mismo sismo, dependiendo del lugar donde se obtengan, las cuales van decreciendo a medida que la distancia desde la zona de ruptura aumenta. La Tabla 1 muestra las intensidades reportadas en distintas ciudades para el evento del 27 de febrero 2010. Se puede observar que el máximo valor alcanzado se reportó en Concepción, alcanzando un valor de IX. Otros registros de intensidades algo menores y más detallados han sido reportados por Astroza et al. (2010).

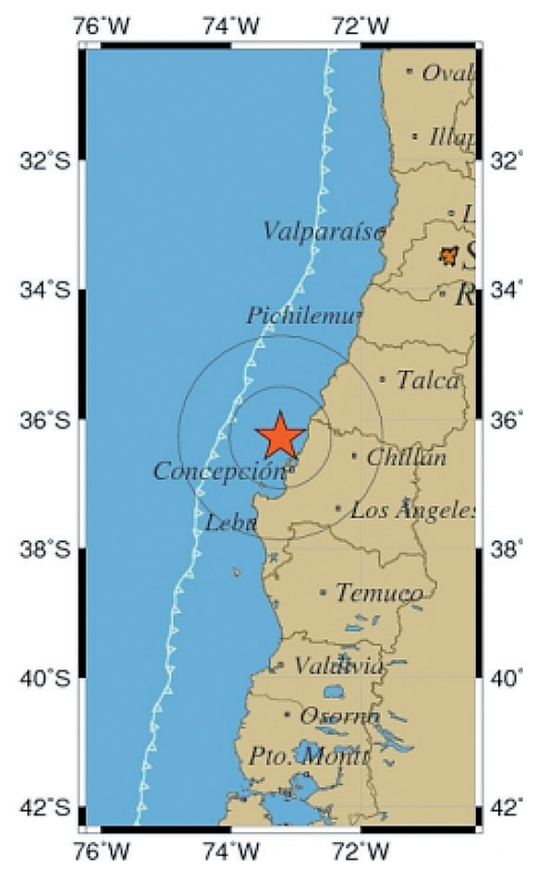

Figura 2: Ubicación del epicentro del sismo de 27 de febrero de 2010 (SSUChile, 2010)

Tabla 1: Intensidades del sismo de 27 de febrero 2010 en ciudades desde Coquimbo a Puerto Montt (ONEMI, 2010)

\begin{tabular}{|c|c|}
\hline Ciudad & Intensidad \\
\hline Coquimbo & III \\
\hline Santiago & VIII \\
\hline Rancagua & VIII \\
\hline Talca & VIII \\
\hline Concepción & IX \\
\hline Temuco & VIII \\
\hline Valdivia & VI \\
\hline Puerto Montt & V \\
\hline
\end{tabular}


Según la descripción de la escala, con un sismo de intensidad IX se produce pánico general. "Las estructuras de albañilería mal proyectadas o mal construidas se destruyen. Las estructuras corrientes de albañilería bien construidas se dañan y a veces se derrumban totalmente. Las estructuras de albañilería bien proyectadas y bien construidas se dañan seriamente. Los cimientos se dañan. Las estructuras de madera son removidas de sus cimientos. Sufren daños considerables los depósitos de agua, gas, etc. Se quiebran las tuberías (cañerías) subterráneas. Aparecen grietas aún en suelos secos. En las regiones aluviales, pequeñas cantidades de lodo y arena son expelidas del suelo".

Como una comparación, el sismo de Chillán de 1939 fue catalogado como intensidad X en la escala de Mercalli. Según reportes oficiales, el $50 \%$ de las construcciones existentes en Chillán colapsaron y unas 5.650 personas fallecieron, aun cuando la prensa contabilizó unos 30.000 (Villavicencio, 2010). Las construcciones de esa época eran principalmente de albañilería sin confinar, madera y adobe, lo que explica el alto porcentaje de estructuras destruidas. Por otro lado, el sismo del 21 de mayo de 1960 sigue siendo el más grande de la historia medido instrumentalmente. Alcanzó una magnitud momento 9.5 y una intensidad VIII en Concepción. Aun cuando la intensidad en Valdivia alcanzó los XI grados. En Concepción y Talcahuano se estimó en más de 10.500 las viviendas destruidas. El puente carretero sobre el río Bío Bío se destruyó en tres partes, especialmente en la zona aledaña a Concepción, donde se derrumbó un tramo de 45 m (Steinbrugge y Flores, 1963; Villavicencio, 2010).

Los dos sismos anteriormente mencionados, más el de 1985 ocurrido en Santiago y Valparaíso, son de gran importancia para el estudio de la ingeniería antisísmica. El sismo de Chillán de 1939 demostró la ineficacia de las albañilerías sin armar para resistir los esfuerzos sísmicos y las bondades de la albañilería confinada. Del mismo modo, el evento de 1960 señaló la considerable importancia que tiene la Mecánica de Suelos y su consideración en los proyectos de ingeniería. De este modo, La Ley de Ordenanza General de Construcciones y Urbanización, vigente desde 1931, fue modificada. Además, en 1972 entró en vigencia la primera Norma Chilena para el cálculo sísmico de edificios NCh 433, la que fue modificada en el año 1996 tras la incorporación de información del terremoto de 1985 (Flores 1998). Por lo tanto, es muy probable que nuevas modificaciones sean implementadas en la norma NCh 433 cuando se analicen los datos obtenidos del sismo del 27 de febrero 2010. Sin embargo, la norma NCh 433 no es directamente aplicable al tipo de estructuración que tienen la mayoría de las iglesias.

\section{Inspecciones realizadas}

Iglesia La Pompeya

Esta iglesia está ubicada en la intersección de Lincoyán y San Martín en Concepción y consta de una estructura en base a muros de albañilería de 1 y $2 \mathrm{~m}$ de espesor aproximadamente con cerchas y pilares de madera y una techumbre de planchas metálicas (Figura 3). La fecha de construcción es de aproximadamente el año 1850, según antecedentes aportados por los sacerdotes de esta iglesia. Por lo tanto posterior al gran terremoto y tsunami ocurrido en Concepción en 1835. El año 1940 se hicieron trabajos de refuerzo de la estructura de la nave central en base a vigas de hormigón armado de una altura aproximada de 1 m que unieron los muros laterales en la parte central de la iglesia y el año 1960 se hicieron trabajos de refuerzo del frontón.

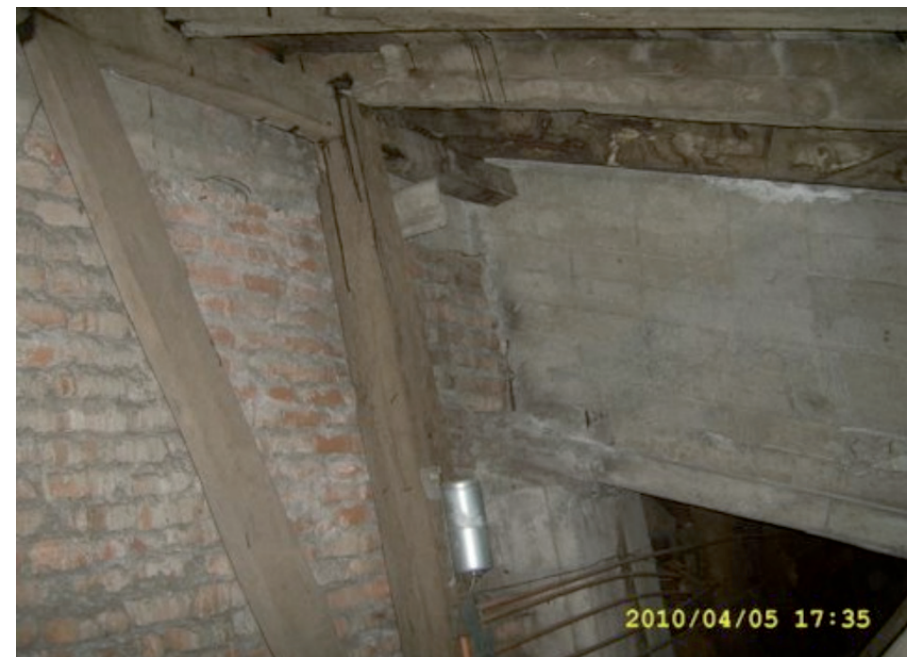

Figura 3: Detalle de la estructura de techumbre de iglesia La Pompeya

La estructura de la iglesia no presenta daños que hagan peligrar su estabilidad. Sólo presentó daños en la fachada lateral y una viga longitudinal. El desplome del antetecho por al lado de San Martín se debió a que la estructura de la 
nave central lo golpeó durante el sismo. La reparación de la iglesia está en su término y como seguridad se eliminó definitivamente el frontis lateral y el daño de la viga longitudinal se reparó con el refuerzo de una viga metálica.

\section{Templo parroquial Jesús Obrero, Schwager, Coronel}

La Iglesia parroquial Jesús Obrero es una obra patrimonial de gran valor construida a principios del siglo XX. La estructura está conformada por un doble muro de albañilería, confinada únicamente por cadenas de hormigón armado, pilares tipo contrafuertes (ver Figura 4 y 5) y una estructura de techumbre de artesonado en madera a la vista (ver Figura 6). La estructura sufrió daños en parte del muro posterior al altar, además, se desplomó parte de los muros y la techumbre de la actual sacristía, la que quedó fuertemente dañada (ver Figura 5). Se observó una grieta horizontal en todo el perímetro de la estructura en la unión de la cadena y los paños de albañilería. En la Figura 6 se observa que la estructura de madera de la techumbre se encuentra en buen estado, sin embargo se revisaron sus anclajes al muro.

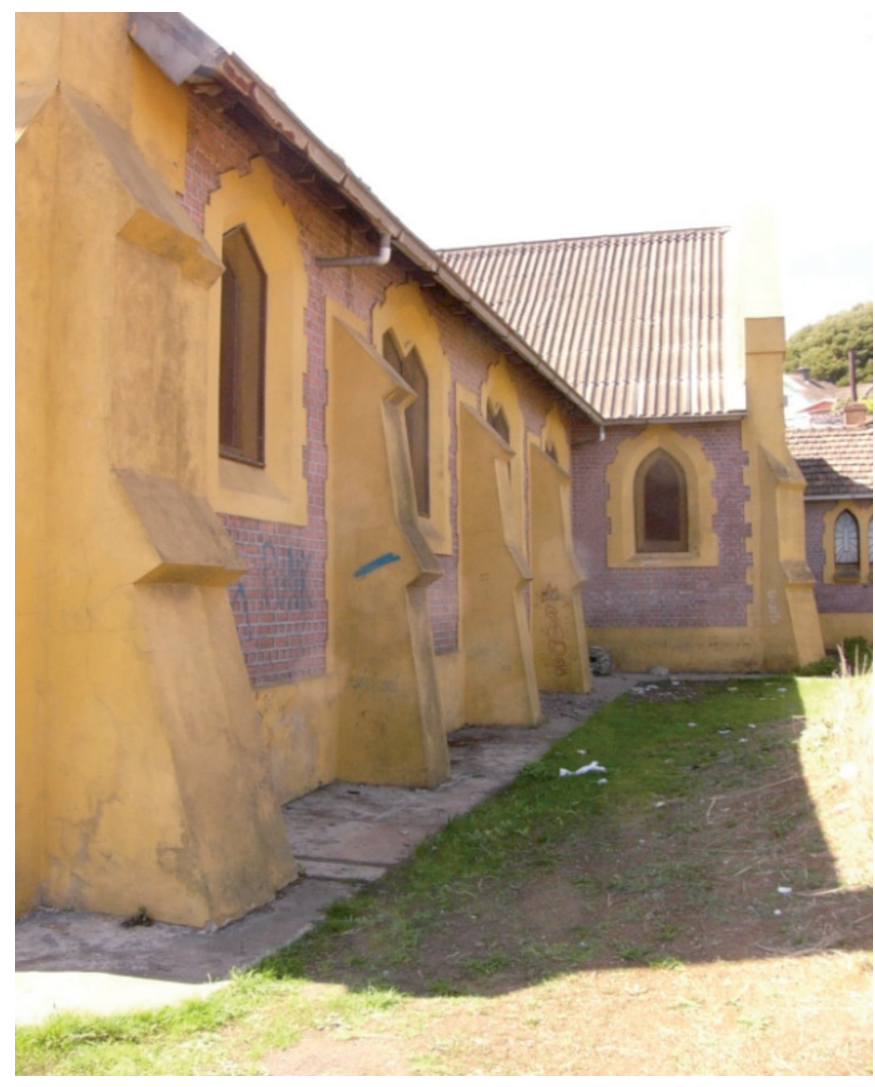

Figura 4. Vista lateral de la estructura con contrafuertes

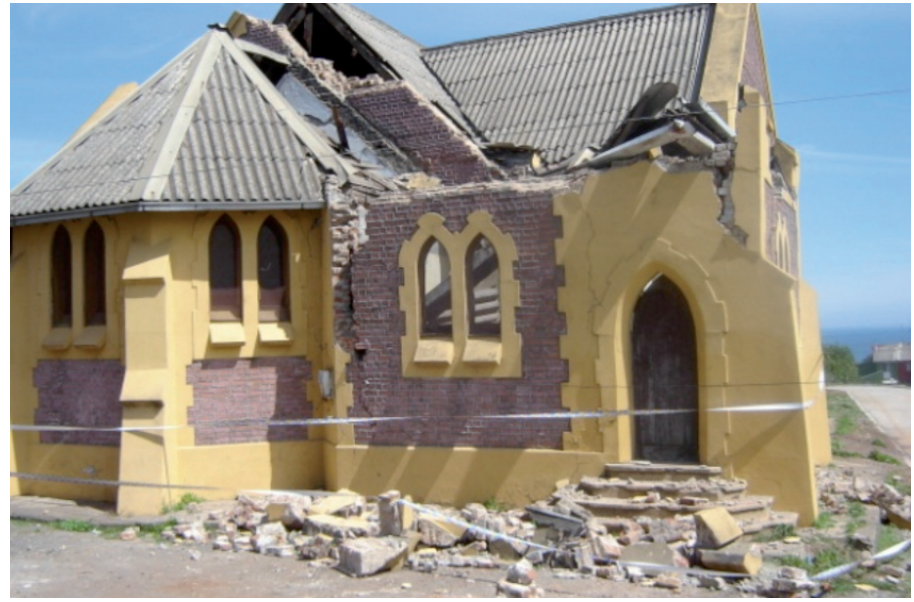

Figura 5: Vista posterior y sacristía parcialmente destruida

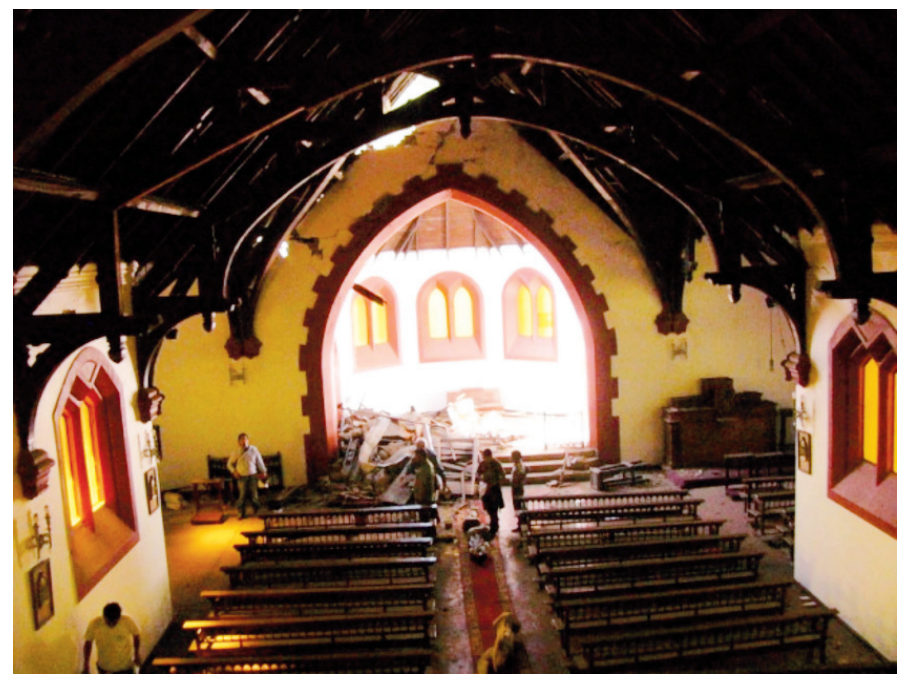

Figura 6: Vista interior de la estructura de techo y muro posterior parcialmente dañado.

En general, los daños sufridos por la estructura la dejan momentáneamente sin uso; sin embargo, por el gran valor patrimonial del templo, se recomienda reconstruir la parte dañada. Para ello se deberá registrar todos los daños de la estructura, teniendo especial cuidado en definir los detalles del tipo de daño y posibles alternativas de reparación, tanto en el interior como en el exterior. Será muy importante recopilar planos e imágenes del proyecto original para mantener las líneas arquitectónicas.

\section{Catedral de Concepción}

La Catedral de Concepción está ubicada en la calle Caupolicán frente a la Plaza de la Independencia. Es una estructura de hormigón armado que comenzó a ser 
construida en 1940, después del terremoto de 1939 que destruyó la anterior catedral reconocible por sus dos altas torres. Se inauguró oficialmente en 1960 y no sufrió mayores daños por el sismo del mismo año. Producto del sismo del 2010, la estructura se calificó como edificio con daño estructural sin compromiso de estabilidad global. En general se observó gran cantidad de grietas en muros susceptibles de ser reparadas devolviendo el monolitismo de la estructura.

Se observaron grietas mayores a $0.4 \mathrm{~mm}$ de ancho y profundidades cercanas a un $75 \%$ del espesor de muro. Todas estas grietas son factibles de ser reparadas devolviendo las capacidades estructurales originales. Se observaron diversas fallas recurrentes en los arcos de naves laterales. Es deseable y tal vez una exigencia técnica antes de reparar verificar la cuantía de acero de esos elementos, ya que debido a las gritas se observó armadura a la vista en varios elementos estructurales.

Las columnas no presentan fallas por aplastamiento o flexocompresión y se observaron sólo fisuras menores en la dirección horizontal. La Figura 7 muestra que en juntas de hormigonado entre pilares y arcos longitudinales se aprecian grietas atribuibles a fallas por adherencia entre estos elementos o por diferencias de rigidez entre ellos.

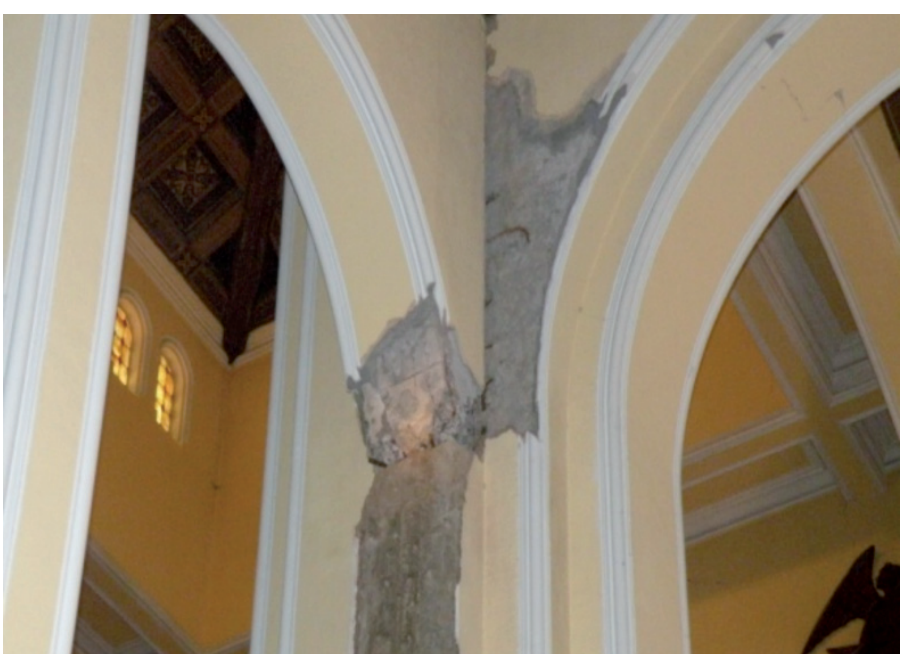

Figura 7: Daño estructural en unión de columnas

Las reparaciones se deben abordar desde un punto de vista de devolver la resistencia estructural perdida producto de las grietas. Estas grietas son factibles de ser reparadas mediante la aplicación adecuada de productos epóxicos de alta resistencia que devuelven el monolitismo de la estructura recuperando así su capacidad original, fundamentalmente respecto a la resistencia y rigidez.

Para solucionar el daño estructural observado en vigas de arcos como se muestra en la Figura 8, se propone la recomposición del hormigón con mortero reforzado con fibras, cuyas características tixotrópicas le permiten ser usado de "sobrecabeza" y sin escurrir. Para las fallas en juntas de hormigonado se propone la aplicación de un producto epóxico inyectado. El desprendimiento de estuco deberá ser repuesto previa instalación de una malla metálica adecuada. Todas las fallas en elementos secundarios deberán ser reparadas aplicando los procedimientos y buenas prácticas de construcción (por ejemplo ver ICH 2011).

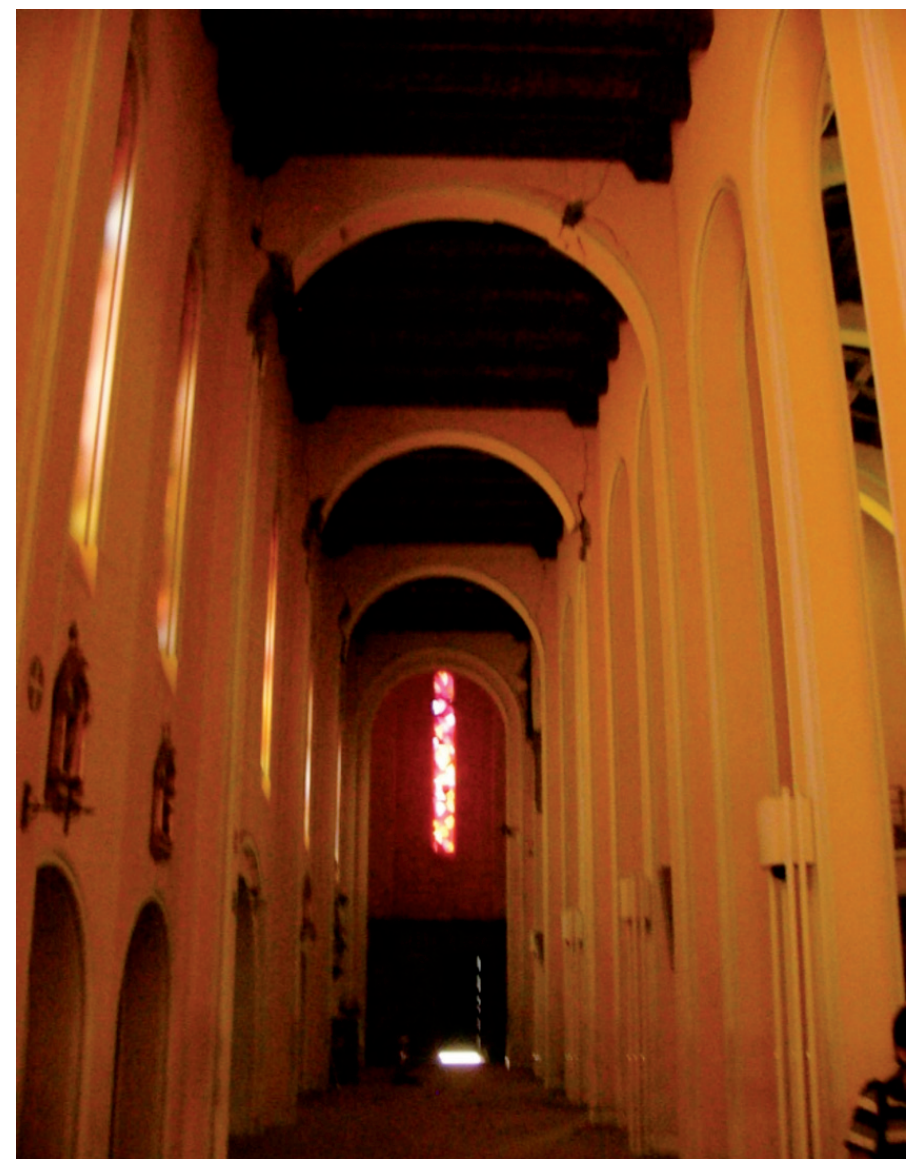

Figura 8: Vista de nave lateral con daños en vigas de arcos

\section{El Sagrario}

La capilla El Sagrario fue construida en el año 1942. Su 
estructuración es en base a marcos de hormigón armado que albergan muros de ladrillos. Esta iglesia sufrió daños en su frontis, principalmente por trabajo longitudinal de la estructura y daños menores en la parte lateral derecha a causa de la interacción con una estructura rígida aledaña.

Su reparación consistió en la generación de una membrana de hormigón capaz de tomar el esfuerzo producido por el desplazamiento longitudinal. Esto se logró generando una losa de cielo que amarró los 2 primeros marcos y el resto fueron reparaciones menores y típicas como inyección de productos epóxicos, morteros de reparación y colocación de dovelas.

El frontón superior de la fachada de la calle está desaplomado, como se observa en la Figura 9. Existen caídas de estucos y cornisas ornamentales de los muros perimetrales (Figura 10). En el frontón posterior (atrás del altar) existe mayor resquebrajamiento. Un pilar lateral está resquebrajado y es donde se produjo desprendimiento de estucos.

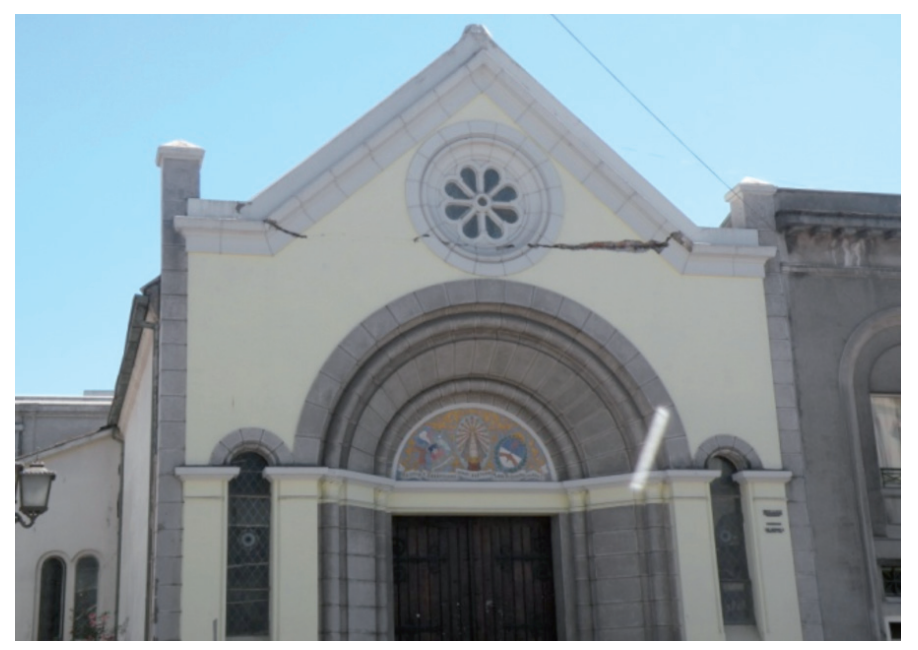

Figura 9: Vista exterior de El Sagrario mostrando daños en frontón

\section{Santuario de Yumbel}

Este templo tiene una data de construcción del año 1856. El muro perimetral del templo es de un espesor superior a $1 \mathrm{~m}$. Está constituido por adobe con albañilería de ladrillo con refuerzos de hormigón armado. En el interior, la estructura de techumbre de madera es sostenida por pilares de madera.

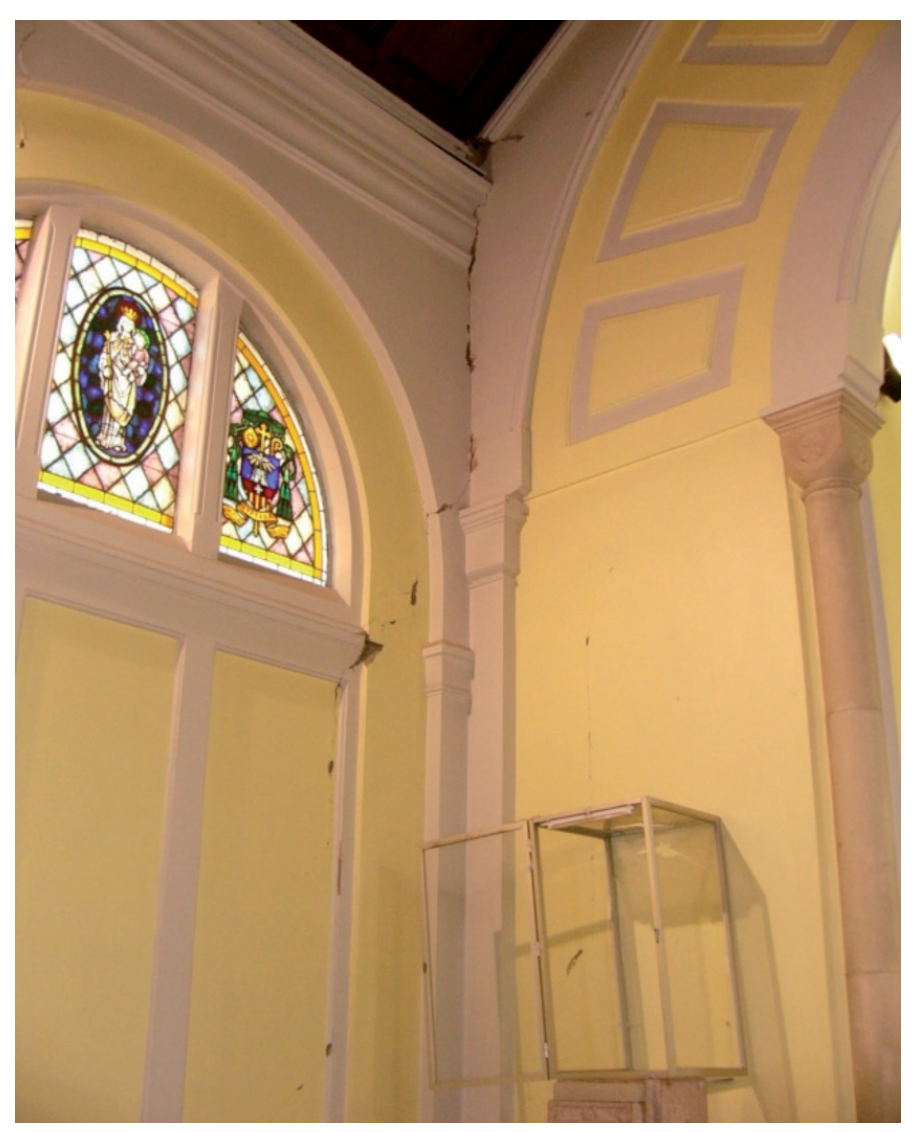

Figura 10: Vista interior con daños en esquina de muros

El campanario funcionó como elemento independiente, por lo que no presenta daños de consideración. Además, éste fue construido posterior al año 1939, pues el original fue destruido en el sismo de ese año. En general, los mayores daños se debieron al deterioro con los años de los materiales de la estructura, y al mal estado de conservación de los elementos de madera (Figura 11). El frontón de la fachada principal mostrado en la Figura 12, es una estructura en voladizo y se debe remover parcialmente para su posterior reparación, es decir, el friso triangular, respetando la altura de los muros perimetrales.

El muro posterior, (atrás del altar) se debe remover parcialmente desde la altura donde comienza el cañón de la nave central, para luego reparar restableciendo las condiciones iniciales.

En la Figura 13 el soporte de la viga izquierda de madera que llega al muro del altar, debe ser reparado y ajustado. La puerta lateral, por la que se accede al colegio, debe ser debidamente señalizada, como vía de escape, y contar 
con un sistema de chapa antipánico, por lo que se debe reubicar la imagen existente actualmente en dicho sector. Se recomienda que el techo del púlpito sea afirmado, por el valor patrimonial que representa. Finalmente, en el segundo piso de la sacristía se deben cambiar los cielos que se muestran en la Figura 14.

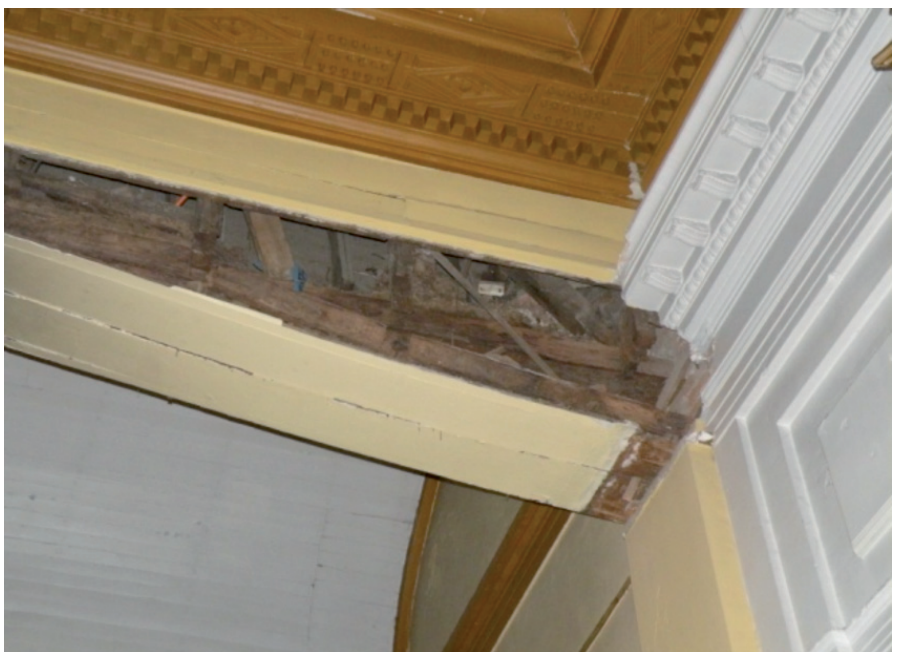

Figura 11: Estructura de techumbre con daños en elementos de madera.

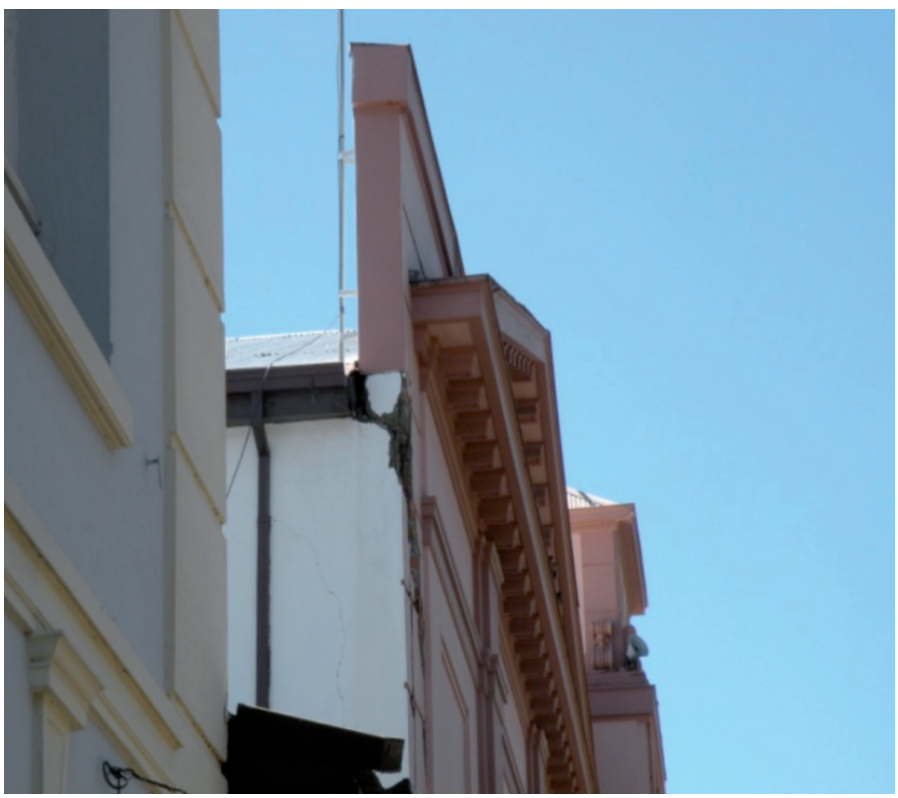

Figura 12: Frontón con daños en su parte superior.

\section{Conclusiones}

El reporte de los daños descritos sólo abarca una pequeña parte de todo el trabajo realizado por la comisión de inspección post-terremoto. Todas las estructuras presentadas en este trabajo fueron construidas en la primera mitad o a mediados del siglo XIX y XX. En general están

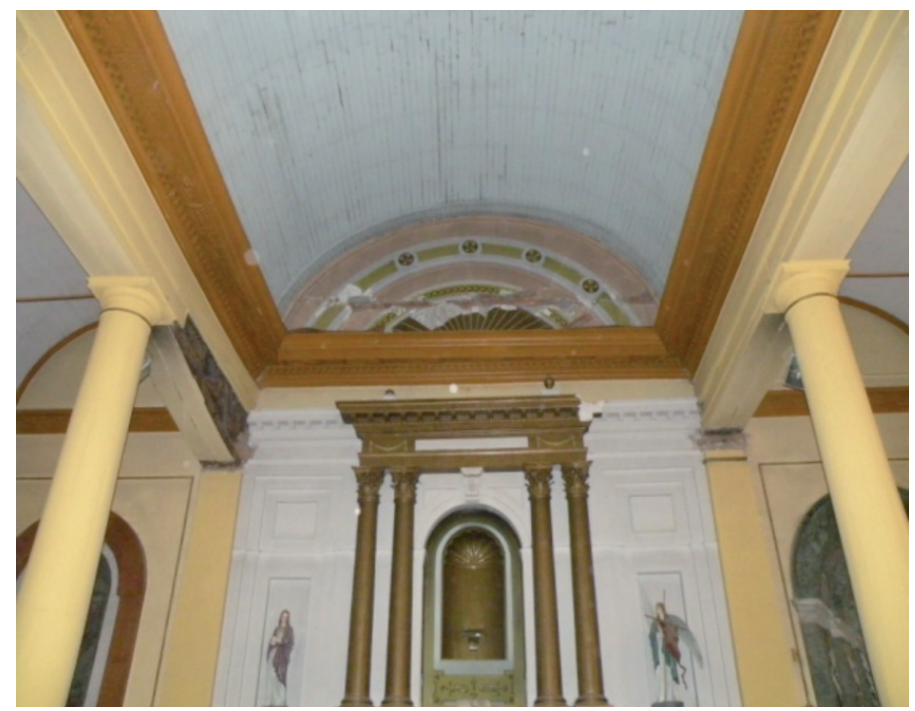

Figura 13: Vista interior y el daño en muro posterior en la parte superior de la nave central.

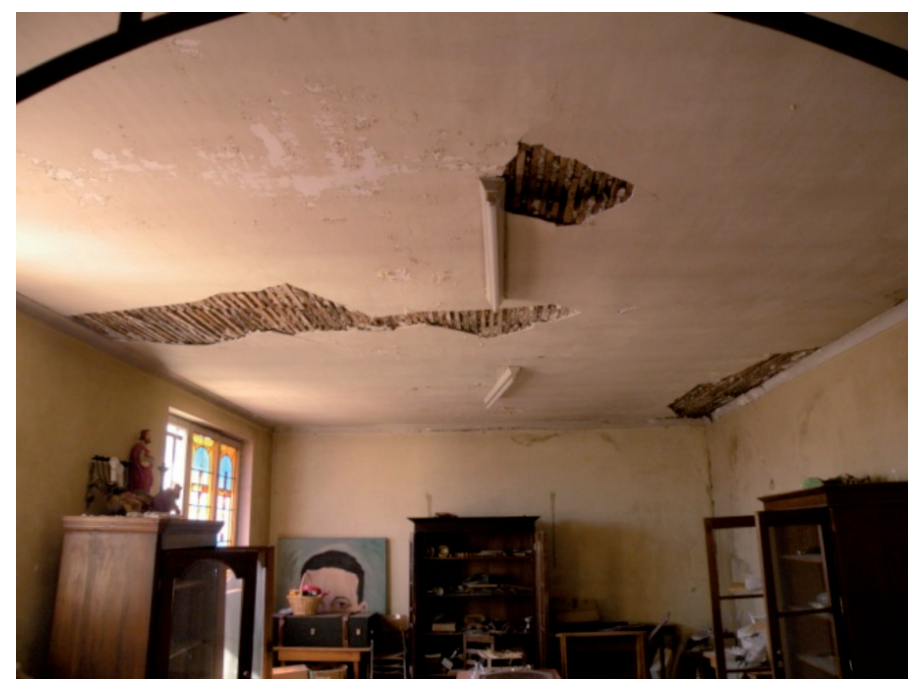

Figura 14: Vista interior de la sacristía con daños en el cielo.

estructuradas en base a gruesos muros de albañilería sin confinar o en hormigón armado con barras sin resaltes. Sin embargo, han soportado al menos dos sismos de gran intensidad.

El patrón de daños se repite en las estructuras de albañilería, esto es, grietas verticales en uniones de muros y grietas horizontales en la base de frontones en voladizo producto del mal o inexistente confinamiento por elementos de hormigón armado. Las estructuras con elementos de hormigón armado, o confinados con cadenas fueron los que mejor comportamiento sísmico mostraron. Finalmente, es importante mencionar que en todos los casos presentados, 
se recomendó reparar o reconstruir las estructuras dañadas debido al gran valor patrimonial y cultural.

\section{Agradecimientos}

Las inspecciones realizadas fueron financiadas por la Vicerrectoría de Asuntos Económicos y Administrativos de la Universidad Católica de la Santísima Concepción.

\section{Referencias}

Astroza, M., Cabezas, F., Moroni, M., Massone, L., Ruiz, S., Parra, E., Cordero, F. y Mottadelli, A. (2010). Intensidades sísmicas en el área de daños del terremoto del 27 de febrero de 2010. Informe del Departamento de Ingeniería Civil de la Universidad de Chile, Santiago

Barrientos, S. (2010). Terremoto Cauquenes 27 febrero 2010. Informe técnico 27 Mayo 2010. Servicio Sismológico de la Universidad de Chile, http://ssn.dgf.uchile.cl/

Betanzo, R. (2010). Daños estructurales y lecciones del terremoto del 27/f en el Gran Concepción. Obras y Proyectos 8, 59- 75

Flores, R. (1998). Ingeniería Sísmica en Chile. Revista Chilena de Ingeniería 111, $\mathrm{N}^{\circ} 3,75-106$

GEER Association (2010). Section 5, Site effects and damage patterns. www.geerassociation.org

ICH (2011). Manual de técnicas de reparación y reforzamiento. Instituto del Cemento y el Hormigón de Chile ICH

ONEMI (2010). www.onemi.cl

Quezada, J., Jaque, E. Belmonte, A., Fernández, A., Vásquez, D. y Martínez, C. (2010). Cambios geomorfológicos ocasionados por el evento sísmico del 27 de febrero 2010 en el centro-sur de Chile. Obras y Proyectos 8, 4-11

Sauter, F. (1989). Fundamentos de Ingeniería Sísmica. Introducción a la Sismología. Editorial tecnológica de Costa Rica

SSUChile Servicio Sismológico de la Universidad de Chile (2010). www.sismologia.cl

Steinbrugge, K.V. and Flores, R. (1963). The Chilean earthquake of May, 1960: a structural engineering viewpoint. Bulletin of the Seismological Society of America 53(2), 225-307

Villavicencio, A. (2010). Terremotos y otros desastres naturales:
Terremoto de Chillán y Valdivia, disponible en línea en http:// www.angelfire.com/nt/terremotoChillan/ 